\title{
Preferensi Habitat Cacing Tanah (Oligochaeta) di Kabupaten Banggai Provinsi Sulawesi Tengah
}

\section{( Habitat Preference of Earthworms (Oligochaeta) in Banggai Districts of Central Sulawesi )}

\author{
Dandi Wahyu Mulyawan ${ }^{1 *}$, Annawaty ${ }^{2}$, Fahri $^{2}$ \\ ${ }^{1}$ Jurusan Biologi, Fakultas MIPA, Universitas Tadulako \\ ${ }^{2}$ Laboratorium zoology fakultas MIPA Universitas Tadulako
}

\begin{abstract}
The goal of this research was to obtain the preference habitat of earthworms in Batui, Banggai District of Central Sulawesi. Purposive randomized sampling was used as sampling method, which was indicated by casting, humidity of soil surface, and plant canopy. Sampling was undertaken in four different land uses (yard, oil palm plantation, cacao plantation, and secondary forests). The samples were collected on a $25 \times 25 \mathrm{~cm}$ plot with 0 until $30 \mathrm{~cm}$ in depth. Specimens preserved in Laboratory of Zoology, Faculty of Science Tadulako University, and its were identified based on Easton (1979). The result showed that the earthworms can be classified into the genus of Planaperethima, which found in the yard. There were 7 out of 11 individuals consists of Planaperethima sp1, Planaperethima sp2, and Planaperethima sp3. The other four samples from the yard were unidentified. Others samples from the palm farms (15 individuals), cacao farms (10 individuals), and secondary forests (14 individuals), were also cauld not be identified, it due to the sample of worms were still in juvenile phase.
\end{abstract}

Key Words: Earthworms, Planaperethima, habitat preference, Banggai, Central Sulawesi.

\begin{abstract}
ABSTRAK
Penelitian ini bertujuan untuk mengetahui preferensi habitat cacing tanah di Batui Kabupaten Banggai Sulawesi Tengah. Metode yang dilakukan untuk penentuan lokasi dalam pengambilan sampel yaitu purposive randomize sampling dengan melihat casting (kotoran cacing tanah), permukaan tanah yang lembab dan luas tutupan tajuk tanaman. Pengambilan sampel dilakukan pada 4 penggunaan lahan yaitu pekarangan rumah, perkebunan kelapa sawit, kebun kakao dan hutan sekunder. Pengambilan sampel menggunakan cangkul, dengan luasan permukaan tanah ukuran $25 \times 25 \mathrm{~cm}$. Tanah digali pada tingkat kedalaman $0-30 \mathrm{~cm}$. Spesimen diawetkan di Laboratorium Zoologi, Fakultas Matematika dan Ilmu Pengetahuan Alam Universitas Tadulako yang diidentifikasi berdasarkan Easton (1979). Cacing tanah yang teridentifikasi tergolong ke dalam genus Planapheretima terdapat pada preferensi habitat pekarangan rumah sebanyak 7 individu dari 11 jumlah individu yang terbagi atas Planapheretima sp1, Planapheretima sp2 dan Planapheretima sp3. Empat individu lainnya di
\end{abstract}


pekarangan rumah tidak dapat diidentifikasi begitu pula dengan cacing tanah yang ditemukan pada lokasi perkebunan kelapa sawit (15 individu), kebun kakao (10 individu) dan hutan sekunder (14 individu) karena masih dalam tahap juvenil.

\section{Sulawesi}

Kata kunci : Cacing tanah, Planapheretima, Preferensi Habitat, Banggai,

\section{LATAR BELAKANG}

Cacing tanah merupakan kelompok hewan filum Annelida kelas Oligochaeta, dengan ciri tubuh memiliki cincin annulus (Edwards and Lofty, 1977). Oligochaeta memiliki karakter dengan sedikit seta, prostomium yang terletak di bagian ujung anterior dan memiliki clitellum (di belakang prostomium). Clitelum merupakan daerah penebalan segmen yang muncul pada bagian tertentu saat cacing mencapai tahap dewasa (Stephenson, 1930).

Distribusi cacing tanah genus Pheretima tersebar sangat luas di Asia Tenggara termasuk di Indonesia. Genus Archipheretima menempati seluruh wilayah pulau Kalimantan dan Philipina. Beberapa genus Metapheretima terdapat di wilayah Papua dan pulau Lombok dan genus Polypheretima terdapat di wilayah Sumatera bagian tengah, seluruh wilayah Sulawesi dan Kalimantan. Genus Planapheretima terdapat di wilayah Kalimantan dan Sulawesi yaitu di bagian tengah dan selatan (Easton, 1979).

Kehadiran jenis cacing tanah sangat ditentukan oleh jenis habitat. Perbedaan habitat dapat berpengaruh pada populasi dan komunitas cacing tanah (Pankhrust, 1994; Lavelle, 1994). Pengolahan tanah secara intensif, pemupukan dan penanaman secara monokultur pada system pertanian konvensional dapat menurunkan populasi cacing tanah.

Terdapat empat areal penggunaan lahan di Kecamatan Batui Kabupaten Banggai yang merupakan habitat cacing tanah. Empat penggunaan lahan tersebut ialah areal pemukiman yaitu pekarangan rumah, perkebunan kelapa sawit dan kebun kakao (kebun masyarakat) dan hutan sekunder. Penelitian ini bertujuan untuk mengetahui preferensi habitat cacing tanah dari genus Planapheretima di Kecamatan Batui Kabupaten Banggai provinsi Sulawesi Tengah. Kami mengoleksi sampel pada empat habitat yaitu pekarangan rumah, perkebunan kelapa sawit, kebun kakao dan hutan sekunder.

\section{METODE PENELITIAN}

Waktu dan Tempat Penelitian

Penelitian ini dilaksanakan di Batui (Gambar 1). Pengambilan sampel

\section{Preferensi Habitat Cacing Tanah (Oligochaeta) di Kabupaten Banggai Provinsi Sulawesi Tengah}

(Dandi Wahyu Mulyawan dkk) 
dilakukan pada waktu pagi hari dan sore hingga malam hari pada bulan Mei-Juli 2015. Pengambilan sampel dilakukan di empat lokasi yaitu pekarangan rumah, perkebunan kelapa sawit, kebun kakao dan hutan sekunder (Gambar 2).

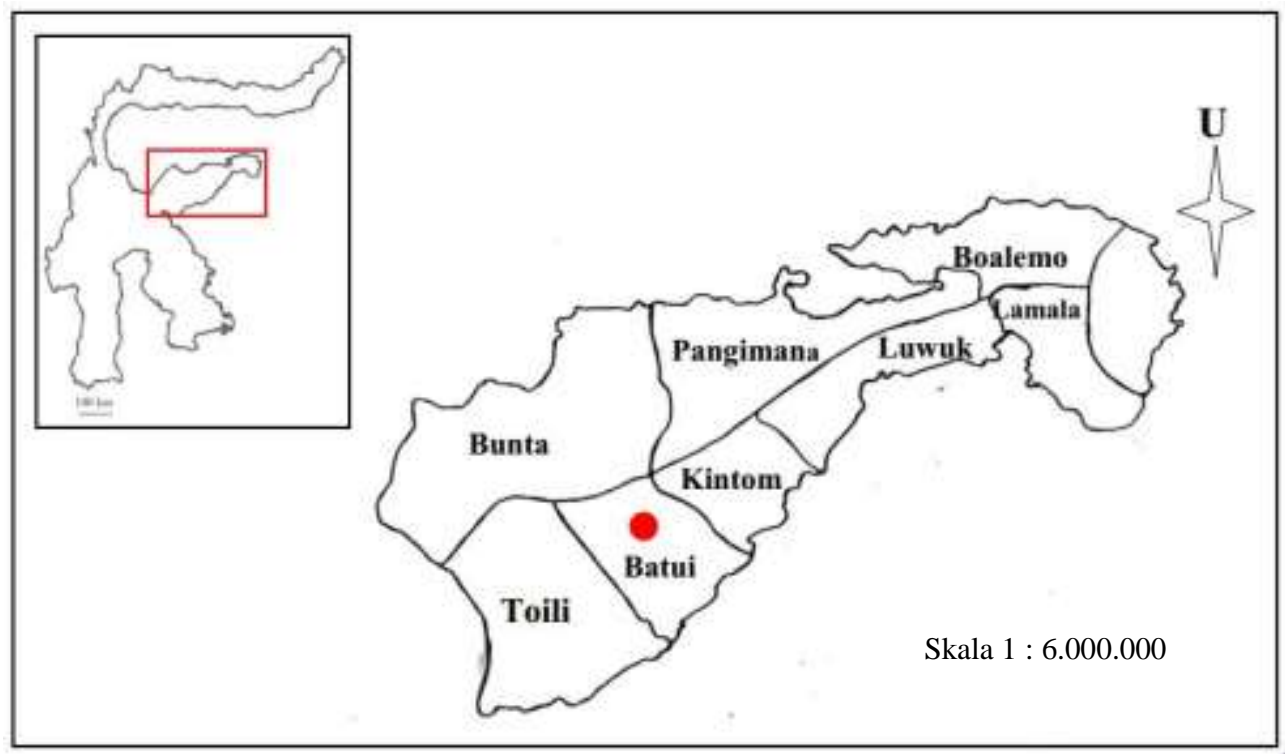

Gambar 1. Peta Lokasi Penelitian di Kabupaten Banggai Sulawesi Tengah. Tanda $=$ titik pengambilan sampel.

\section{Teknik pengambilan sampel}

Di setiap lokasi ditentukan 4 titik pengambilan sampel. Penentuan lokasi pengambilan sampel menggunakan metode purposive randomize sampling dengan melihat casting (kotoran cacing tanah), permukaan tanah yang lembab dan luas tutupan tajuk tanaman. Pengambilan sampel menggunakan cangkul pada permukaan tanah dengan ukuran $25 \times 25$ cm. Koleksi dilakukan pada tingkat kedalaman 0 - $30 \mathrm{~cm}$, dan dilakukan pengulangan sebanyak 3 kali pada hari yang berbeda.

Sampel cacing tanah yang telah dikoleksi dimasukkan ke dalam botol sampel dengan pengawetan bertingkat yaitu alkohol $30 \%$ (1-5 menit, atau hingga cacing tanah tidak aktif bergerak), $50 \%$ (30 menit, hingga cacing tanah tidak aktif bergerak) danalkohol $70 \%$ (untuk dibawa ke Laboratorium) (Afriani, 2015).

Identifikasi sampel dilakukan di Laboratorium Zoology Jurusan Biologi Fakultas MIPA Universitas Tadulako menggunakan kunci identifikasi Easton (1979). Data hasil penelitian dianalisis secara deskriptif. Data koleksi cacing tanah di setiap habitat dan karakter identifikasi ditampilkan dalam bentuk tabel. 

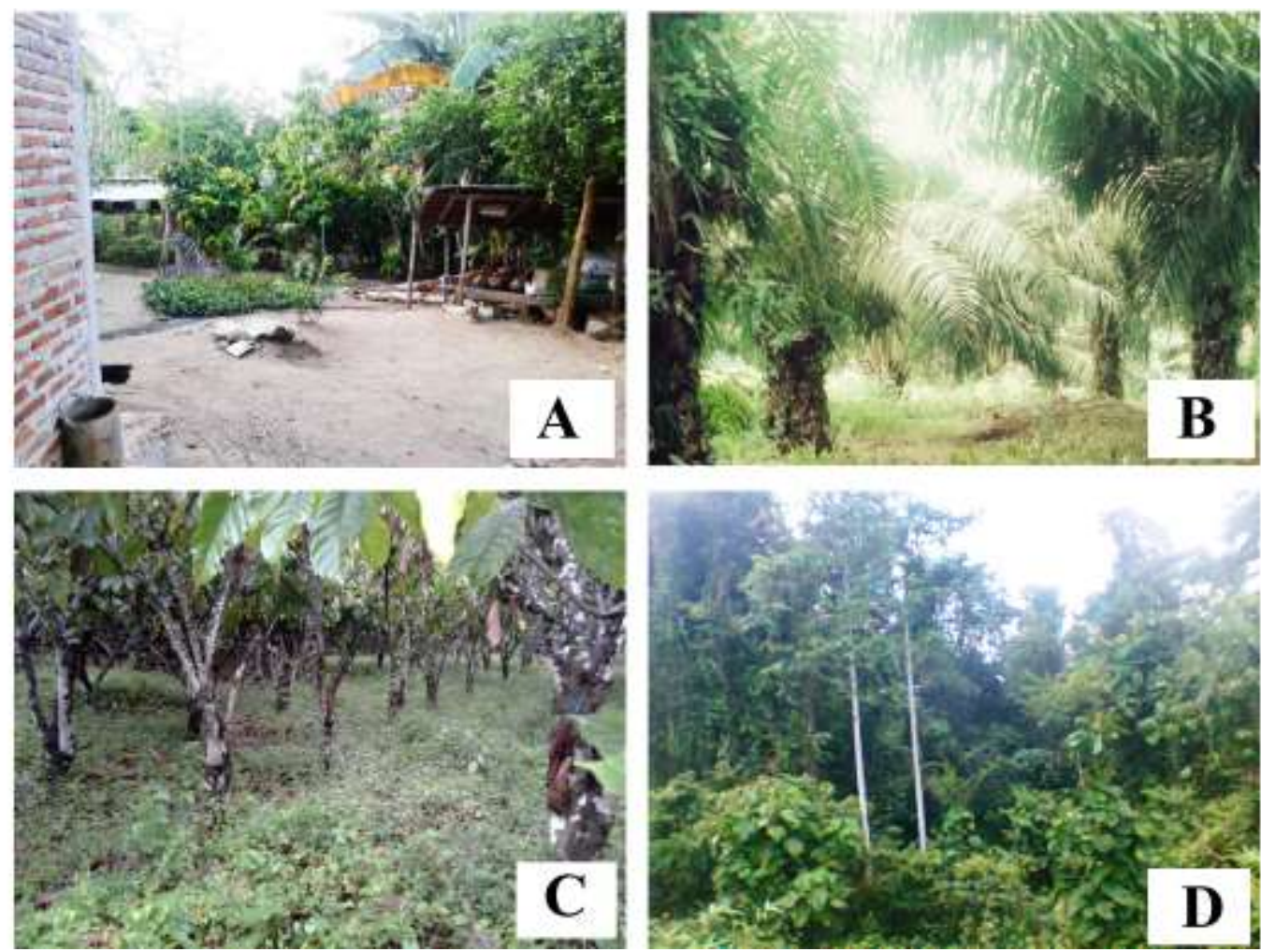

Gambar 2. Lokasi Pengambilan Sampel : a) Pekarangan rumah, b) Perkebunan kelapa sawit, c) Kebun kakao, d) Hutan sekunder.

HASIL

Cacing tanah yang dikoleksi sebanyak 52 individu dari semua lokasi pengambilan sampel yang termasuk genus Planapheretima, family Megascolecidae (Tabel 1). Lokasi pengambilan sampel hutan sekunder (titik I) terdapat 14 individu, perkebunan kelapa sawit (titik II) sebanyak 15 individu, kebun kakao (titik III) sebanyak 10 individu dan pekarangan rumah (titik IV) sebanyak 11 individu (Tabel 2).

Tabel 1 Jenis-jenis cacing tanah yang dikoleksi dalam lokasi pengambilan sampel

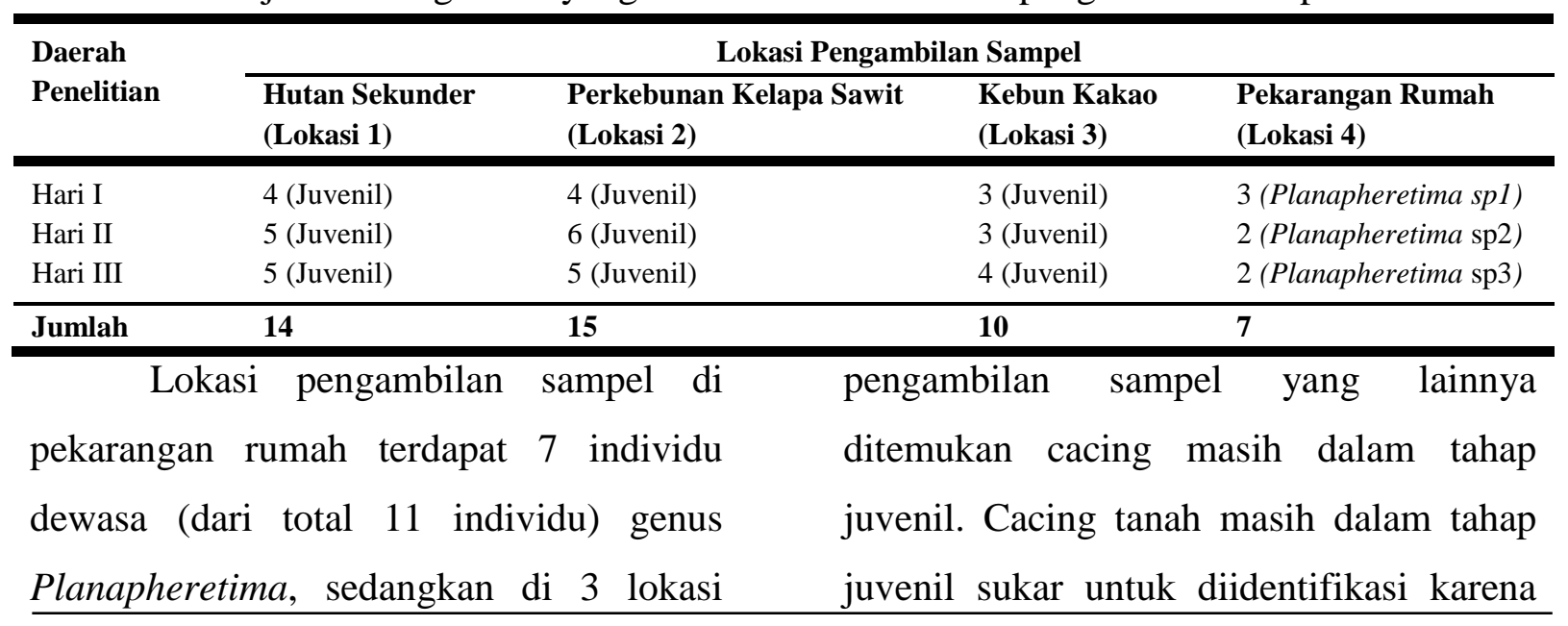

Preferensi Habitat Cacing Tanah (Oligochaeta) di Kabupaten Banggai Provinsi Sulawesi Tengah

(Dandi Wahyu Mulyawan dkk) 
karakter penting belum berkembang secara sempurna.

\section{PEMBAHASAN}

Perkebunan kelapa sawit (lokasi 2) memiliki jumlah sampel terbanyak, diikuti hutan sekunder (lokasi 1), pekarangan rumah (lokasi 4), dan kebun kakao (lokasi 3). Meskipun lokasi pekarangan rumah memiliki jumlah yang lebih sedikit dibandingkan dengan perkebunan kelapa sawit dan hutan sekunder, namun dilokasi ini ditemukan cacing yang telah dewasa sehingga teridentifikasi sebagai genus Planapheretima.

Pekarangan rumah merupakan lokasi pilihan habitat dari cacing tanah genus Planapheretima memiliki kondisi permukaan tanah yang lembab terdapat tanaman mangga Mangifera sp. serta adanya aliran air yang kecil dan tutupan tajuk rapat sehingga mengurangi cahaya matahari sampai di permukaan tanah. Hal ini sesuai laporan (Notohadiprawiro, 1998) bahwa cacing tanah lebih menyukai keadaan lembab.

Lokasi pengambilan sampel dari lokasi 1-3 yaitu hutan sekunder, perkebunan kelapa sawit dan kebun kakao memiliki kondisi tanah yang kering. Keadaan makanan dan lingkungan yang terlalu kering menyebabkan suatu proses dehidrasi pada tubuh cacing tanah. Hal ini dapat terlihat dari warna cacing tanah yang pucat atau berubah menjadi gelap dan akhirnya akan mati (Suwardjo, 1987).

Tabel 2 Karakter kunci morfologi dan anatomi cacing tanah genus Planapheretima

\begin{tabular}{|c|c|c|c|c|c|c|c|}
\hline \multirow[b]{2}{*}{ Spesies } & \multicolumn{7}{|c|}{ Ukuran, bentuk, tipe dan letak pada segmen } \\
\hline & $\begin{array}{l}\text { Panjang } \\
(\mathrm{cm})\end{array}$ & $\begin{array}{l}\text { Diameter } \\
(\mathrm{cm})\end{array}$ & $\begin{array}{l}\text { Jumlah } \\
\text { segmen }\end{array}$ & $\begin{array}{l}\text { Tipe } \\
\text { Prostomium }\end{array}$ & Gizzard & Clitellum & $\begin{array}{l}\text { Jumlah } \\
\text { Setae }\end{array}$ \\
\hline Planapheretimasp1 & 10,8 & 0,4 & 128 & Open epilobous & 8 & 13-15Annular & $45-49$ di VI \\
\hline Planapheretimasp2 & 11,3 & 0,5 & 130 & Open epilobous & 8 & 13-15Annular & $40-50$ di VI \\
\hline Planapheretima $\mathrm{sp} 3$ & 11 & 0,4 & 128 & Prolobous & 8 & 13-15Annular & $50-60$ di VI \\
\hline
\end{tabular}

Cacing tanah yang di perkebunan kelapa sawit, kebun kakao dan pekarangan rumah, ditemukan pada kedalaman $0 \mathrm{~cm}-$ $15 \mathrm{~cm}$, dengan demikian bahwa cacing tanah yang ditemukan termasuk tipe Epigeis. Cacing tanah di hutan sekunder ditemukan pada kedalaman $15-30 \mathrm{~cm}$ yaitu cacing tanah yang hidup dan aktif pada lapisan permukaan tanah, tidak membuat lubang dan pemakan serasah.
Bouche (1977) melaporkan bahwa cacing tanah tipe Epigeis merupakan cacing tanah yang hidup dan aktif pada lapisan permukaan tanah, tidak membuat lubang dan pemakan serasah dan tipe Endogeis memiliki tubuh lebih besar yang aktif membuat lubang, memakan bahan organik tanah dan hidup di kedalaman $\pm 20 \mathrm{~cm}$ dari permukaan tanah. Tiga jenis cacing tanah yaitu Planapheretima sp1,

\section{Preferensi Habitat Cacing Tanah (Oligochaeta) di Kabupaten Banggai Provinsi Sulawesi Tengah}

(Dandi Wahyu Mulyawan dkk) 


\section{Planapheretima sp2, dan Planapheretima} sp3 yang ditemukan di pekarangan rumah tidak dapat diidentifikasi hingga tingkat spesies karena tidak adanya karakter yang sesuai dengan kunci identifikasi yang tersedia. Cacing tanah yang ditemukan pada tipe habitat perkebunan kelapa sawit, kebun kakao dan hutan sekunder masih tahap juvenile, karena kondisi lokasi yang kering sehingga mempengaruhi keberadaan cacing tanah.

Cacing tanah yang teridentifikasi tergolong dalam genus Planapheretima yang terdapat pada preferensi habitat pekarangan rumah sebanyak 7 individu dari 11 jumlah individu dan cacing tanah yang ditemukan pada lokasi perkebunan kelapa sawit (15 individu), kebun kakao (10 individu) dan hutan sekunder (14 individu) tidak dapat teramati karena masih dalam tahap juvenil.

\section{UCAPAN TERIMA KASIH}

Terima kasih kepada Sami Bukang, S.P. dan Nurul Aisyah, S.Si. atas bantuannya selama proses penelitian, juga kepada Moh.Akbar dan Rusdin yang telah membantu selama pelaksanaan sampling di lapangan.

\section{DAFTAR PUSTAKA}

Afriani, 2015. Jenis - Jenis Dan Karakteristik Cacing Tanah (Annelida : Oligochaeta) Pada Tiga Tipe Penggunaan Lahan. Skripsi Penelitian (dalam persiapan) Jurusan Biologi Fakultas Matematika dan Ilmu Pengetahuan Alam. Universitas Tadulako Palu.

Bouche, M. B. 1977. Strategies lombriciennes. In Soil Organisms as Components of Ecosystems (eds. U. Lohm and T. Persson). Biol. Bull. 25 : 122-132.

Easton, E.G. 1979. A revision of the 'acaecate' earthworms of the Pheretima Group (Megascolecidae: Oligochaeta): Archipheretima, Metapheretima, Planapheretima, Pleionogaster and Polypheretima. London.

Edwards, C.A. and Lofty, J.R. 1977. Biology of earthworms, second ed. Chapman and Hall Ltd., London. P:1-71.

Lavelle P. 1994. Soil Funa and Sustainable Land Use in the Humid Tropics. In DJ Greenland and I Szabolcs (eds). Soil Resiliense and Sustainable Land Use. $C A B$ International. Oxon.

Notohadiprawiro, T. 1998. Tanah dan Lingkungan. Jakarta : Direktorat Jenderal Pendidikan Tinggi. Departemen Pendidikan dan Kebudayaan.

Pankhrust CE. 1994. Biological Indicators of Soil Healthand Sustainable Productivity.In So/7 Resiliense and Sustainable Land Use. DJ Greenland and I Szabolcs(eds). $C A B$ International. Oxon.

\section{Preferensi Habitat Cacing Tanah (Oligochaeta) di Kabupaten Banggai Provinsi Sulawesi Tengah}


Stephenson, JM.BD.Sc. 1930. The Oligochaeta. Inggris: Oxford at the Clarendon Press.

Suwardjo, H. 1987. Peranan Bahan Organik Terhadap Aktivitas Cacing Tanah (Perionyx exavatus) dalam petikan ekologi tanah. Kumpulan hasil seminar. Fakultas biologi UKSW, 20-22 november, 1987 : 62-68 